Spanish Adaptation of the Autism Spectrum Disorders - Diagnosis for Adults (ASD-DA) in Adults with Severe and Profound Intellectual Disability

\title{
Inmaculada Planelles-Fernández,
}

David Gallardo-Pujol, Antonio Labad, David Godall, Natalia Cristia, Alfonso Gutiérrez-Zotes, et al.

Journal of Developmental and Physical Disabilities

ISSN 1056-263X

J Dev Phys Disabil

DOI 10.1007/s10882-017-9541-5
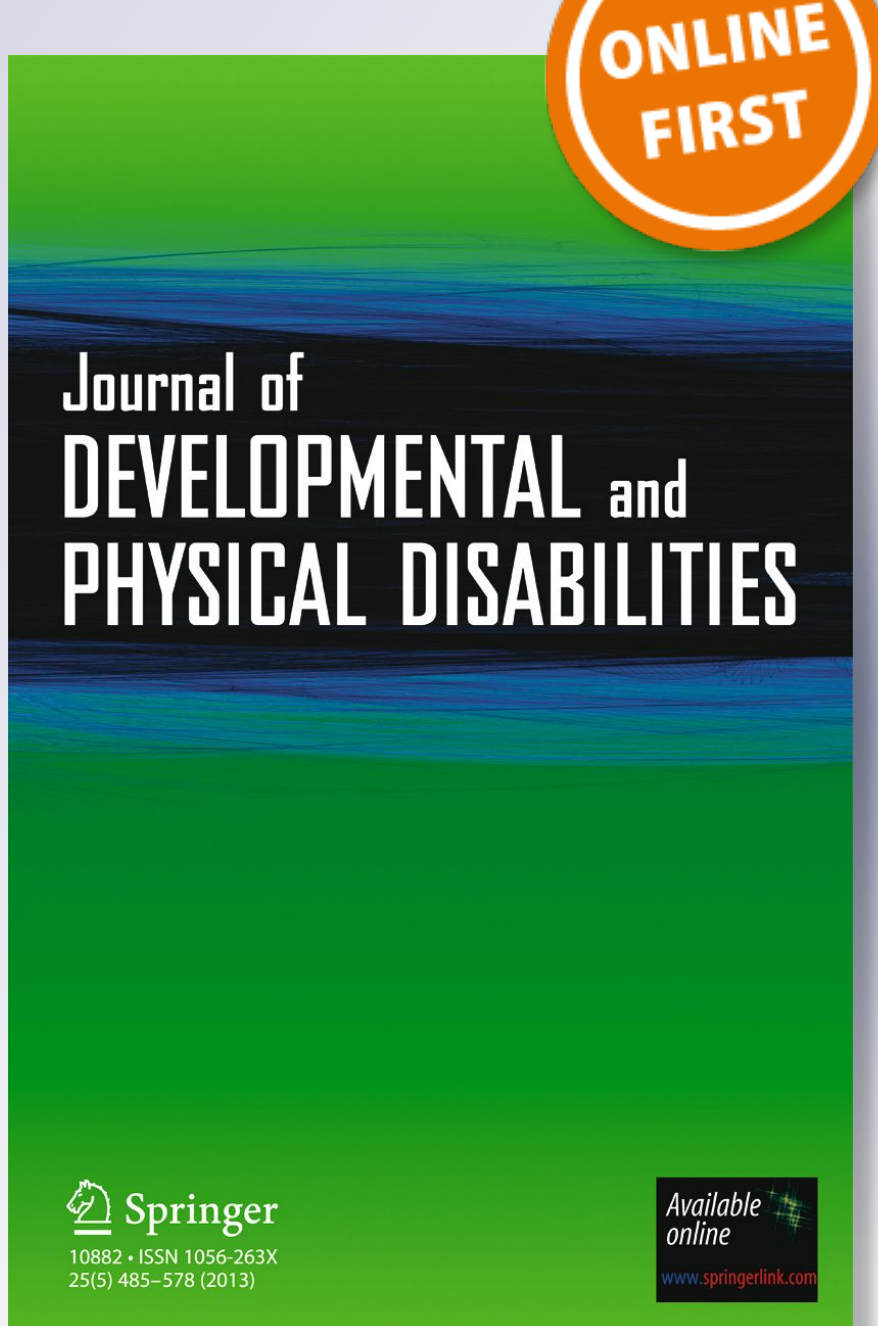
Your article is protected by copyright and all rights are held exclusively by Springer Science +Business Media New York. This e-offprint is for personal use only and shall not be selfarchived in electronic repositories. If you wish to self-archive your article, please use the accepted manuscript version for posting on your own website. You may further deposit the accepted manuscript version in any repository, provided it is only made publicly available 12 months after official publication or later and provided acknowledgement is given to the original source of publication and a link is inserted to the published article on Springer's website. The link must be accompanied by the following text: "The final publication is available at link.springer.com". 


\title{
Spanish Adaptation of the Autism Spectrum Disorders - Diagnosis for Adults (ASD-DA) in Adults with Severe and Profound Intellectual Disability
}

\author{
Inmaculada Planelles-Fernández ${ }^{1}$ • David Gallardo-Pujol ${ }^{2,3}$ • \\ Antonio Labad ${ }^{4}$ - David Godall ${ }^{1}$ - Natalia Cristia ${ }^{1}$. \\ Alfonso Gutiérrez-Zotes ${ }^{4}$ • Johnny L. Matson ${ }^{5}$
}

(C) Springer Science+Business Media New York 2017

\begin{abstract}
The Autism Spectrum Disorders - Diagnosis for Adults (ASD-DA) with intellectual disability was designed to quickly provide relevant information to establish a diagnosis of the most common Autism Spectrum Disorders (ASD) (autism, pervasive developmental disorder not otherwise specified and Asperger's syndrome) (Matson et al. 2007a). The ASD-DA was adapted and translated into Spanish and administered to a sample of 156 adults with severe $(n=67,42.9 \%)$ and profound $(n=89,57.1 \%)$ intellectual disability. Seventy-one (45.5\%) participants had a diagnosis of intellectual disability and autism spectrum disorder, and the other eighty-five (54.5\%) had a diagnosis of intellectual disability without autism spectrum disorder. The reliability scores of the scales implied values in the "good-to-excellent" range (0.78-0.95), and test-retest reliability was obtained with good values for most of the items on the scale. A three-factor structure was replicated via confirmatory factor analysis. Participants with and without ASD showed significant differences in the three ASD-DA scales and in their total scores. Using a receiver operating characteristics (ROC) curve, a score of 21
\end{abstract}

Alfonso Gutiérrez-Zotes gutierreza@peremata.com

1 Residencia Marinada, Fundación Villablanca, Universitat Rovira i Virgili, Reus, Spain

2 Facultat de Psicologia, Universitat de Barcelona, Barcelona, Spain

3 Institute of Neurosciences, University of Barcelona, Barcelona, Spain

4 Hospital Psiquiátrico Universitario Pere Mata, IISPV, CIBERSAM, Universitat Rovira i Virgili, Reus, Spain

5 Department of Psychology, Louisiana State University, Baton Rouge, LA, USA 
on the ASD-DA scale showed good specificity (0.97) and sensitivity (0.92) values with respect to DSM-IV-TR criteria.

Keywords Autism spectrum disorders $\cdot$ ASD — DA - Intellectual disability · Reliability

\section{Introduction}

The DSM-5 (American Psychiatric Association 2013) provides a new diagnosis of autism spectrum disorder (ASD) encompassing previous DSM-IV-TR diagnoses of autistic disorder (autism), Asperger's disorder, childhood disintegrative disorder, Rett's disorder, and pervasive developmental disorder not otherwise specified. ASD is now characterized by deficits in two criteria: deficits in social communication and social interaction and restricted repetitive patterns of behavior, interests, and activities. Therefore, the social communication domain merges key symptoms from the DSMIV social and communication domains.

Autism spectrum disorders are included, in turn, within a broader "neurodevelopmental disorders" category. Symptoms must be present in the early developmental period and cause clinically significant impairment in social, occupational, or other important areas of current functioning. The criterion $\mathrm{C}$ states that these disturbances are not better explained by intellectual disability (intellectual developmental disorder) or global developmental delay.

Intellectual disability (ID) is a disorder with an onset during the developmental period that includes both intellectual and adaptive functioning deficits in conceptual, social, and practical domains. An individual's level of ID can range from mild to profound (American Psychiatric Association 2013). The DSM-5 emphasizes the need to use both clinical assessments and standardized testing of intelligence when diagnosing ID, with the severity of impairment (mild, moderate, severe...) based on adaptive functioning rather than IQ test scores alone. These criteria are in contrast to those prescribed by the DSM-IV, in which IQ denoted severity. The assessment of intelligence across three domains (conceptual, social, and practical) ensures that clinicians base their diagnosis on the impact of deficits in general mental abilities on functioning needed for everyday life. As a result, this diagnosis based on the impact of the deficit on functioning would provide a more accurate diagnosis in cases of comorbidity with ASD.

ID and ASD frequently co-occur. In fact, it has been considered that the disorders with the greatest overlap with ID are those in the autism spectrum (Wilkins and Matson 2009). ID in combination with ASD typically leads to more severe phenotypes and impairments compared with ID alone. Approximately $40 \%$ of the ID population meets the diagnostic criteria for ASD (Arvio and Sillanpää 2003; Matson and Shoemaker 2009). Other studies have concluded that approximately $70 \%$ of people with autism (Magnússon and Sæmundsen 2001) have a diagnosis of ID, representing a significant proportion of the ID diagnosed in the severe or profound range.

It is difficult to diagnose ASD in people who have low levels of intellectual functioning due to a lack of tests adapted for the psychological assessment of this population. In recent years, there has been a breakthrough in the concept of ID and in our understanding of the real needs and capacities of people with intellectual disabilities as well as of the significant potential for their development and learning. There is a 
need for clinical criteria that allow for an accurate diagnosis of ASD to be determined in people with ID.

In the population of adults with ID, diagnosing autism can be a complex task. ID is associated with alterations in the three major domains of functioning on which the diagnosis of autism is based. According to the Diagnostic Manual of Mental Retardation (Fletcher et al. 2007), in adults with severe or profound ID, the complete absence of speech, severe repetitive behaviors and difficulties with social interaction are common. In these people, reduced mental ages are associated with less social development and poor communicative behaviors, with some overlap in these areas between people with ID and autistic disorders (DiLavore et al. 1995).

However, some authors believe that in cases of ID and ASD, it is possible to recognize the comorbid presence of an ASD (de Bildt et al. 2003). Although people with ID and ASD and those with severe or profound ID exhibit similar symptoms, it is possible to make distinctions between the two groups (Matson et al. 2007b). Several studies have established that the co-occurrence of ASD and ID is associated with increased social and communication impairment, higher rates of restricted, repetitive behaviors (RRBs), and the presence of more severe and more long-term challenging behaviors (Matson and Shoemaker 2009; McCarthy et al. 2010).

The behavioral presentation and symptomology differs when ID and ASD co-occur. A study that included 307 adults with severe or profound ID who were separated into two groups, ASD + ID and ID only, found differences in symptomology when using the Diagnostic Assessment for the Severely Handicapped-II (DASH-II) (Matson et al. 1991). The ASD-ID group exhibited more symptomology on the scales of anxiety, mania, schizophrenia, stereotypies/tics, self-injurious behavior, eating disorders, sexual disorders, and impulse control than the ID only group (Cervantes and Matson 2015). Thus, the presence of ASD may serve as a vulnerability factor for increased psychopathology within the ID population (La Malfa et al. 2007).

The presence of psychiatric disorders and ASD in particular significantly affects the quality of life of people with ID and their families. Improving the diagnosis and treatment of people with ID and ASD should be a priority throughout the entire life cycle, including a renewed focus on adulthood. Several factors justify the importance of diagnosing the co-occurrence of ASD in adults with ID: a high estimated prevalence of co-comorbidity between 25 and 39\% (Bryson et al. 2008; Fombonne 2011; Kim et al. 2011; Sappok et al. 2010), the fact that ASD often remains undetected in people with ID until adulthood (La Malfa et al. 2004; Sappok et al. 2010), the common occurrence of diagnostic overshadowing in persons with ID (Reiss et al. 1982), the overlapping symptoms in ID and ASD (Matson and Shoemaker 2009; Sappok et al. 2014a), and the lack of recognition of ASD because of the use of antipsychotic medications in ID (Spencer et al. 2013). Similarly, the results of some studies on the presence of a specific ASD phenotype in adults with ID could justify the development and use of specific measures in this population. The transition to adulthood in people with ASD and ID could involve behavioral and symptomatological modifications. These changes involve an assessment of new clinical manifestations of the disorder. A study prospectively investigating the changes in autism symptoms and maladaptive behaviors found that individuals with ID had more autism symptoms and maladaptive behaviors than those without ID and that they improved less over time (Shattuck et al. 2007). In people with ASD, the presence of ID has been related to a greater severity of autism symptoms, 
worse overall outcomes, and a decreased likelihood of improvement (Lord and Bailey 2002; McGovern and Sigman 2005; Nordin and Gillberg 1998; Seltzer et al. 2004; Shea and Mesibov 2005).

Several scales have been designed or subsequently validated to screen for ASD in adults with ID. The Social Communication Questionnaire (SCQ) (Rutter et al. 2003) is a 40-item clinical caregiver-report screening instrument for ASD that has been used in children and adolescents (Allen et al. 2007). There are lifetime and current versions of the SCQ. The SCQ is derived from the Autism Diagnostic Interview-Revised (ADI-R) (Lord et al. 1994) and is increasingly used in research and clinical practice. Recently, the use of the SCQ-current version for ASD screening in adults with ID has been supported (Sappok et al. 2015). The Autism Diagnostic Interview-Revised (ADI-R) (Lord et al. 1994) is a standardized, semi-structured interview that covers ASD symptomatology and developmental history (Rutter et al. 2003). The ADI-R diagnostic algorithms have been found to be over-inclusive for individuals with nonverbal mental ages below 18 months and those with severe to profound ID (Nordin and Gillberg 1998; Risi et al. 2006). The ADOS is a semi-structured, standardized instrument for the observation of social and communicative behaviors, play and the imaginative use of materials that are characteristic of autism. The development of the instrument was based on two previous instruments, the Pre-Linguistic Autism Diagnostic Observation Scale (PL-ADOS) (DiLavore et al. 1995) and the Autism Diagnostic Observation Scale (ADOS) (Lord et al. 1989). The original ADOS was designed to be used for children aged 5-12 years who had at least some expressive language skills. The Pre-Linguistic Autism Diagnostic Observation Schedule (PL-ADOS) was developed as an alternative version to be used with very young children (younger than 3 years) or children with no language skills. The A-PL-ADOS was designed to assess older low-functioning individuals with little or no language skills. In a clinical sample of adults with ID who were suspected of also having ASD, the ADOS was over-inclusive, as reflected by a reduced level of specificity in diagnosing ASD and autism. With increasing severity of ID and comorbidity of ASD, the feasibility of the ADOS was reduced (Sappok et al. 2013). ADI-R and ADOS measures are time-consuming and can only be applied to a limited number of adults with ID (Sappok et al. 2013; Sappok et al. 2014b). To date, several instruments have been developed specifically for screening ASD in adults with ID. The Diagnostic Behavioral Assessment for ASD_Revised (DiBAS-R) (Sappok et al. 2014b) is a DSM-5/ICD-10-based 19-item screening scale. The scale consists of two DSM-5 domains corresponding to the assessment of typical ASD behaviors in social communication and interaction and stereotyped and restrictive behaviors and sensory interests. The ACL is a screening scale based on the ICD-10 that aims to identify ASD in suspected cases (Sappok et al. 2014c).

The Music-Based Assessment for Autism Spectrum Disorders (MUSAD) was developed as a diagnostic observational instrument within an interactive music framework. It is based on the ICD-10/DSM-5 criteria for ASD and was designed to assess adults with a lower level of functioning, including individuals with severe language impairments (Bergmann et al. 2015).

The Pervasive Developmental Disorder in Mental Retardation Scale (PDD-MRS) (Kraijer and de Bildt 2005) is a simple classification and screening instrument devised to identify autistic disorders in persons with mild to profound ID. Table 1 shows the main scales used to assess symptoms of ASD with ID. 
Matson and coworkers (Matson et al. 2007a) designed a battery of scales that can diagnose ASD in a population of adults with severe and profound intellectual disabilities. The ASD-DA was developed together with two other scales that enable the evaluation and later follow-up of the treatment of behavioral disorders and psychiatric comorbidity associated with ASD in a population of adult participants with severe and profound ID. The ASD-DA is an instrument designed to evaluate autism, ASD not otherwise specified and Asperger's syndrome throughout the life cycle in adults with severe and profound ID (Matson et al. 2007a). This study had three aims: 1) to translate and adapt the validated version of the ASD-DA into Spanish; 2) to obtain the psychometric properties of reliability and the results of a confirmatory factor analysis, together with the coefficients of sensitivity and specificity, in a sample of participants with ID with or without autism; and 3) to determine whether the Spanish version of the ASD-DA can correctly distinguish between adults with ID with and without ASD based on the symptoms listed in the DSM-IV-TR (American Psychiatric Association 2000) and ICD-10 (World Health Organization 1992) guidelines.

\section{Methods}

\section{Participants}

The sample consisted of 156 adults with severe ID $(n=67,42.9 \%)$ and profound ID $(n=89,57.1 \%)$. A total of $65.4 \%(n=102)$ were men. The average age of sample was 48.11 years $(S D=13.93)$. All participants were residents or users of day centers in Residencia Marinada, Villablanca Servicios Asistenciales and Hospital Psiquiatrico Universitario Pere Mata, Reus, Spain). These centers are specialized residential units that care for adults with ID. The sample characteristics are shown in Table 2.

Group assignments were made based on the DSM-IV-TR and ICD-10 diagnostic criteria. A questionnaire comprising 11 items based on the DSM-IV-TR and ICD-10 criteria (Charman et al. 2005) was administered to direct care staff by a licensed psychologist specializing in ASD with years of experience in the care of adults with ID and ASD. The clinical interviews were audio-recorded. From the recordings, a second independent rater $(\mathrm{PhD}$, degree in Clinical Psychology) evaluated the participants based on the direct care staff's endorsement of the 11 items on the DSM-IV-TR / ICD-10 checklist. Both raters were required to endorse three or more symptoms to arrive at a PDDNOS diagnosis (two or more symptoms in the social interaction domain, one or more symptoms in the communication domain, and no symptoms in the stereotyped behavior domain). To diagnose autism, both raters were required to endorse two or more symptoms in the social interaction domain, one or more symptoms in the communication domain, and one or more symptoms in the stereotyped behavior domain. The sample of people in this study had been admitted to the unit for at least one year before evaluation, which allowed us to observe their behavior in different contexts of everyday life. The answers to the questionnaire items by the caregiver were based on direct observations of these behaviors and on information provided by their families when necessary. There were no missing data in our sample. Group assignments were made independent of any previous ASD diagnoses. All procedures were 


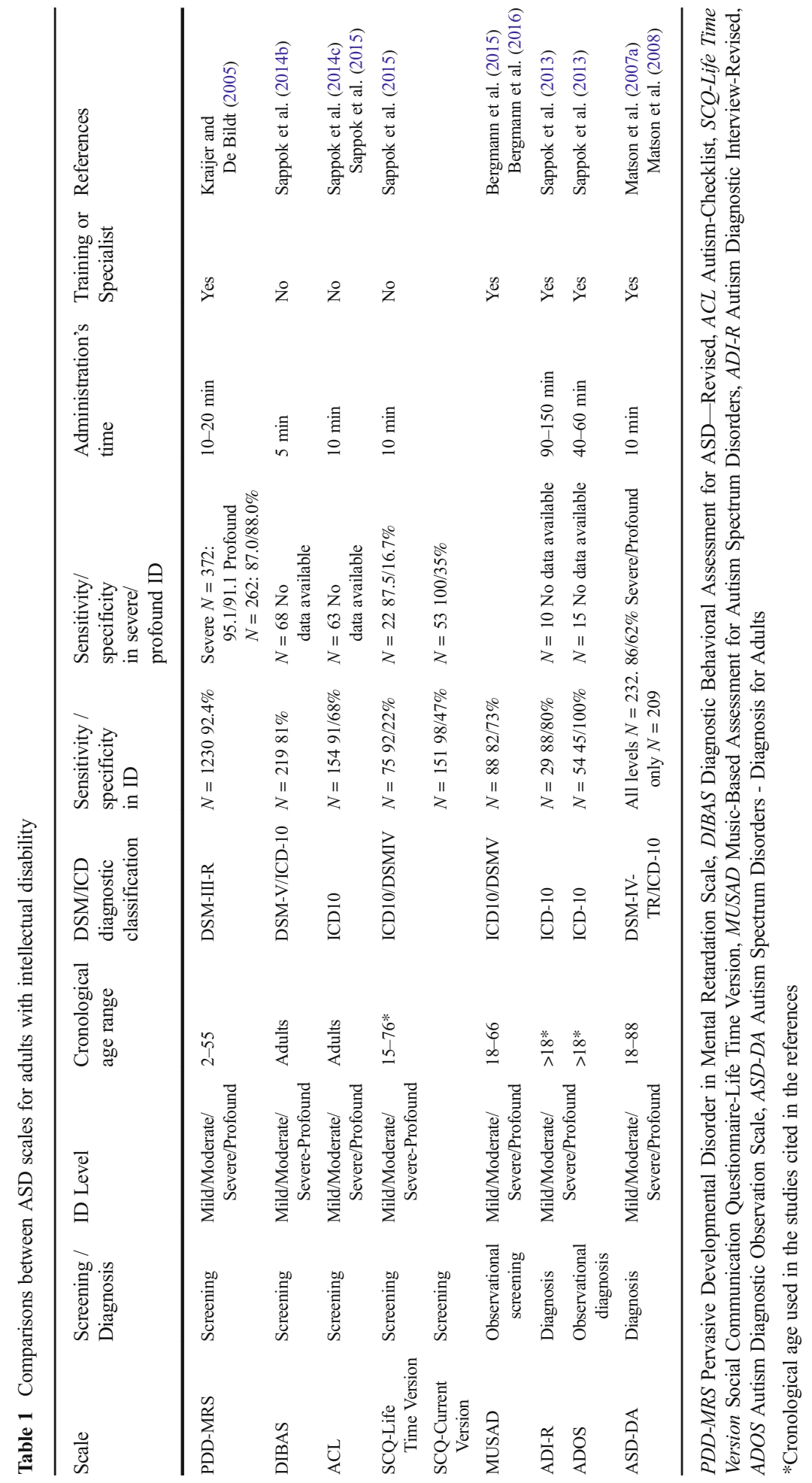


implemented in accordance with the Declaration of Helsinki. Ethical approval was obtained from the institutional review board. Family member or legal representatives provided written informed consent.

\section{Instruments}

Our study is part of a wider study in which different tests adapted to people with ID were used. The assessment battery includes the DASH-II (Matson et al. 1991), ABC (Aman et al. 1985), ICAP (Bruininks et al. 1986), CARS (Schopler et al. 1980), and MESSIER (Matson et al. 1999) in addition to the ASD-BPA (Matson and Rivet 2007) and ASD-CA (Matson and Boisjoli 2008) tests that are part of the ASD-A battery (Matson et al. 2007a). As with the ASD-DA, the MESSIER tests, ASD-CA and ASDBPA scales were translated into Spanish to be included in our study. Our study began in 2008, and the scales were administered between 2009 and 2014. When our study began, there were no scales that had been adapted to diagnose autism in the population of people with severe and profound levels of ID in Spain. The ASD-DA scale was specifically designed to assess ASD in people with ID, particularly at the severe / profound levels. The scale assesses people within a broad age range of 18 to 88 years. The ASD-DA is a diagnosis scale. It was constructed as a measure to assist with the differential diagnosis of autism, PDD-NOS, and Asperger's Syndrome across the lifespan. The scale was developed with the notion that persons with ID alone and those with ID and ASD could be differentiated from each other based on observable symptoms. Standardized instructions for administration of the scale were also developed (Matson et al. 2007a). This scale can be administered in approximately $10 \mathrm{~min}$ (Matson et al. 2008).

The ASD-DA (Matson et al. 2007a) consists of 31 items with three scales: social impairment, impairment in communication, and repetitive/restrictive interests or behaviors. The scale scores items as either $(0)=$ not different, no impairment or $(1)=$ different, some impairment. The items on the ASD-DA were derived from the DSM-IVTR and ICD-10 criteria for autism, PDD-NOS, and Asperger's syndrome and from items on other diagnostic scales for autism (e.g., the Childhood Autism Rating Scale [CARS] and the autism/PDD-NOS subscale of the DASH-II), as well as from a comprehensive research review of the ASD literature, diagnostic guidelines, and critical incidents and observations noted by experienced clinicians working with this population (Matson et al. 2007a). The interrater and test-retest reliabilities are adequate, and the internal consistency is excellent (Cronbach's alpha $=.94)$ (Matson et al. 2007a). The descriptions and results of the psychometric properties of the ASD-DA scale can be found elsewhere (Matson et al. 2007a). The diagnostic utility of the ASD-DA has been demonstrated by a cut-off that differentiates between adults with ID with and without autism (Matson et al. 2007b). The authorization to adapt the ASD-DA to Spanish was obtained from Matson (J. Matson, personal communication 2008). Translation-backtranslation of the ASD-DA was performed, and the consensus regarding the final scale items was subsequently approved by Matson.

The ASD-DA was administered by a Ph.D. psychologist with training and experience in working with people with intellectual disabilities. A staff member with knowledge of at least one year of residents was the informant. The rater recorded descriptions 
Table 2 Sample characteristics $(N=156)$

\begin{tabular}{ll}
\hline Patients & Sample distribution \% (N) \\
\hline Gender & $65.4(102)$ \\
Male & $34.6(54)$ \\
Female & \\
Diagnosis of intelectual disability & $42.9(67)$ \\
Severe & $57.1(89)$ \\
Profound & $45.5(71)$ \\
Diagnosis of intelectual disability with autism or PDD-NOS & $54.5(85)$ \\
Diagnosis of intelectual disability without autism or PDD-NOS & \\
\hline
\end{tabular}

PDD-NOS pervasive developmental disorder not otherwise specified

of the behaviors of residents in different contexts of everyday life. If there was any doubt regarding any conduct, clarification was requested from the resident's family. The assessment was audio-recorded.

The Spanish version of the ASD-DA is shown in Appendix 1.

\section{Statistical Analysis}

Descriptive statistics, mean differences with t-tests, and alpha internal consistencies for all subjects were analyzed. Pearson correlation was used to obtain the relationship between the total score on the final version of the ASD-DA and the total score on the DSM-IV-TR checklist. The test-retest reliability of the ASD-DA was analyzed using Cohen's kappa. The coefficients for sensitivity and specificity were obtained using the receiver operating characteristics (ROC) curve with the DSM-IV-TR criteria. These analyses were carried out using version 17.0 of SPSS (Chicago, IL) software. A confirmatory factor analysis was conducted using Weighted Least Squares Means and Variance (WLSMV) estimation for categorical data via Mplus 7.3. Goodness-offit was assessed with common fit indices (Jackson et al. 2009): $\chi^{2}$, comparative fit index (CFI), root mean square error of approximation (RMSEA), and weighted root mean squared residual (WRMR) using conventional thresholds (Marsh et al. 2004). For identification purposes, the latent factor variances were fixed to 1. According to Wolf et al. (2013), the sample size required to reliably estimate models with eight indicators per factor and factor loadings of approximately 8 is approximately 100 individuals. This is the minimum sample size, below which the estimates and the coverage could bias the results. In our case, our sample size met the requirements suggested by Wolf et al. (2013) with respect to this issue.

\section{Results}

To replicate the factor structure of the original version, we tested the fit of a three-factor model in which the ASD-DA items reflected the latent variables (social, communication and behavioral). The chi-square value for the model was 646.206 with 431 degrees 
of freedom $(p<.001)$. The RMSEA was $0.06(90 \% \mathrm{CI}=0.05 \div 0.07)$. The $\mathrm{CFI}$ value was of 0.99 , whereas WRMR was 1.19. All indices indicated a close relative fit, though not an exact fit. Figure 1 shows the standardized factor loadings for each factor. The intercorrelations between the latent factors were high. The intercorrelation between the communication and social scales was 0.92 . The correlation between the behavior and social scales was 0.95 , whereas the correlation between the behavior and communication scales was 0.87 .

The reliability of the whole scale was 0.96 . Cronbach's alpha coefficients were 0.95 for the social scale (16 items), 0.78 for the communication scale ( 8 items), and 0.78 for the behavioral scale ( 7 items). These scores imply values in the "good-to-excellent" range. Test-retest reliability using Cohen's kappa was computed for all 31 items $(N=49)$. The results are presented in Table 3 . The values for the individual items ranged from 0.380 to 0.959 ( $p<0.01$ ), with the exception of item $2(-0.021)$.

Pearson's correlation coefficient between the total score on the final version of the ASD-DA and the total score on the DSM-IV-TR checklist was $0.87(p<0.000)$.

Independent samples t-tests revealed that the ASD group obtained significantly higher scores than the non-ASD group on the social scale $(\mathrm{M}=15.23, \mathrm{SE}=1.29$ [ASD group]; $\mathrm{M}=5.60, \mathrm{SE}=4.16$ [no ASD group]; $\mathrm{t}(102.82)=20.19, p<.001$; Cohen's $d=3.01)$, communication scale $(\mathrm{M}=7.91$, $\mathrm{SE}=1.10$ [ASD group]; $\mathrm{M}=5$, $\mathrm{SE}=2.14$ [no ASD group]; $\mathrm{t}(129.96)=10.90, p<.001$; Cohen's $d=1.66)$; behavior scale $(\mathrm{M}=4.12, \mathrm{SE}=1.24$ [ASD group]; $\mathrm{M}=.80, \mathrm{SE}=.98$ [no ASD group]; $\mathrm{t}$ $(132.51)=18.65, p<.001$; Cohen's $d=3)$; and the total of the three scales $(M=27.03$, $\mathrm{SE}=2.35$ [ASD group]; $\mathrm{M}=11.40, \mathrm{SE}=6.42$ [no ASD group]; $\mathrm{t}(109.77)=20.81$, $p<.001$; Cohen's $d=3.12$ ).

Figure 2 shows the ROC of the ASD-DA score and DSM-IV-TR criteria. Table 4 shows the sensitivity, specificity, and area under the curve (AUC) of the ROC analysis for the target cut-off scores. A score of 21 on the ASD-DA showed the best values for specificity (0.97) and sensitivity (0.92) with respect to the DSM-IV-TR criteria.

\section{Discussion}

The main objective of this study was to adapt and analyze the psychometric properties of a Spanish version of the ASD-DA for intellectually disabled adults. Diagnosing ASD in adults with ID represents a clinically significant objective, and the availability of evidence-based diagnostic instruments is desirable to support clinicians in the differential diagnosis of ID and ASD (Matson and Shoemaker 2009; Sappok et al. 2015). There is an urgent need for an instrument that is specifically able to identify ASD in persons with ID of all levels of functioning (particularly the more severe levels) and of all ages (Kraijer and de Bildt 2005). Our sample consisted of adults with severe and profound ID with or without ASD. A three-factor structure of the original scale (Matson et al. 2007a) was tested for replication. All items significantly loaded on the specified factor, yielding a close fit to the data. This finding suggests that the factor structure of the present instrument is stable. However, a cautionary note must be made. When we examined the sources of the exact misfit of the model, we found that two items of the Behavioral factor (item 3 and item 28) could have important cross-loadings on the Social factor, as suggested by modification indices and the residual matrix, 
which could partially explain why we did not achieve an exact fit. Future versions of this instrument should address this issue, perhaps by rewording some of these items.

With respect to its internal consistency, the scale showed good reliability, with an alpha of 0.78 . The social scale had a reliability of 0.95 , the communications scale 0.78 , and the total scale 0.96 . The reliability values of the total and social scales are similar to those obtained in the original version of the instrument (Matson et al. 2007a). The scales for communication and repetitive/restrictive interests or behaviors had a lower reliability in our sample. Additionally, the test-retest reliability results showed that 26 of the 31 items had a correlation above 0.65 , with only item 2, Age-appropriate self-help and adaptive skills (i.e., reliable care of self), not showing a significant correlation. The Spanish version of the ASD-DA had a correlation of 0.87 with the overall score on the DSM-IV-TR checklist, supporting the construct validity of the scale with users in Spain. This value is higher than that obtained in the American sample (Matson et al. 2007a). Because the ASD scale was designed to distinguish participants with autism among people with broader overall ID (Matson et al. 2007a), it was expected that higher scores would represent people with a higher likelihood of autism on all scales. This is precisely the result we obtained in our study. Thus, users with severe / profound ID and autism scored higher on all three scales and total ASD-DA score. Therefore, all sub-scales of the Spanish version of the ASD-DA can differentiate adults with severe / profound ID with ASD from those without these disorders. The ASD-DA is a diagnosis scale. Therefore, its application is intended for the appropriate detection and classification of people with disease to allow them to benefit from specific treatment. To determine the cut-off point, we sought to maximize the sensitivity, as the proportion of positive cases that were correctly identified as such. Our results show that a total ASDDA score of 21 is the best cut-off point because it implies a good combination of sensitivity and specificity. However, this score is higher than that used for the American version of the ASD-DA scale, which had a cut-off of 19 points. Sensitivity and specificity estimates found in the current study for the ASD-DA are similar or higher than that of other common diagnostic scales (see Table 1).

This study aimed to contribute to the development of knowledge in identifying ASD in adults with the most severe levels of ID. The ASD-DA was designed for the sole purpose of assessing symptoms of ASD in this population. The results of our sample of the Spanish population confirm the discriminant validity and effective diagnosis of the ASD-DA scale, differentiating between adults with severe/profound ID and ASD and adults with severe/profound ID only.

Our study's main objective was the adaptation of the ASD-DA to Spanish. These results are based on the DSM-IV-TR criteria and not on the new DSM-5 criteria for two reasons: 1) the theory underlying the ASD-DA was defined by the DSM-IV-TR / ICD10 criteria, and 2) when we designed our study six years ago, the DSM-5 had not been published and the new ASD criteria were unknown. One implication of the comparison of the ASD-DA with the DSM-IV-TR and not the DSM-5 is that our results do not reflect the changes in the new criterion of hyper-or hyporeactivity to sensory input or unusual interest in sensory aspects of the environment. However the ASD-DA includes items 5 and 11 to evaluate sensorial alterations. Future analysis of the ASD-DA-scale with DSM-5 criteria must be performed.

One of the strengths of this study is the unusually high sample size, given the difficulties in assessing patients with severe / profound ID. This number remains high 


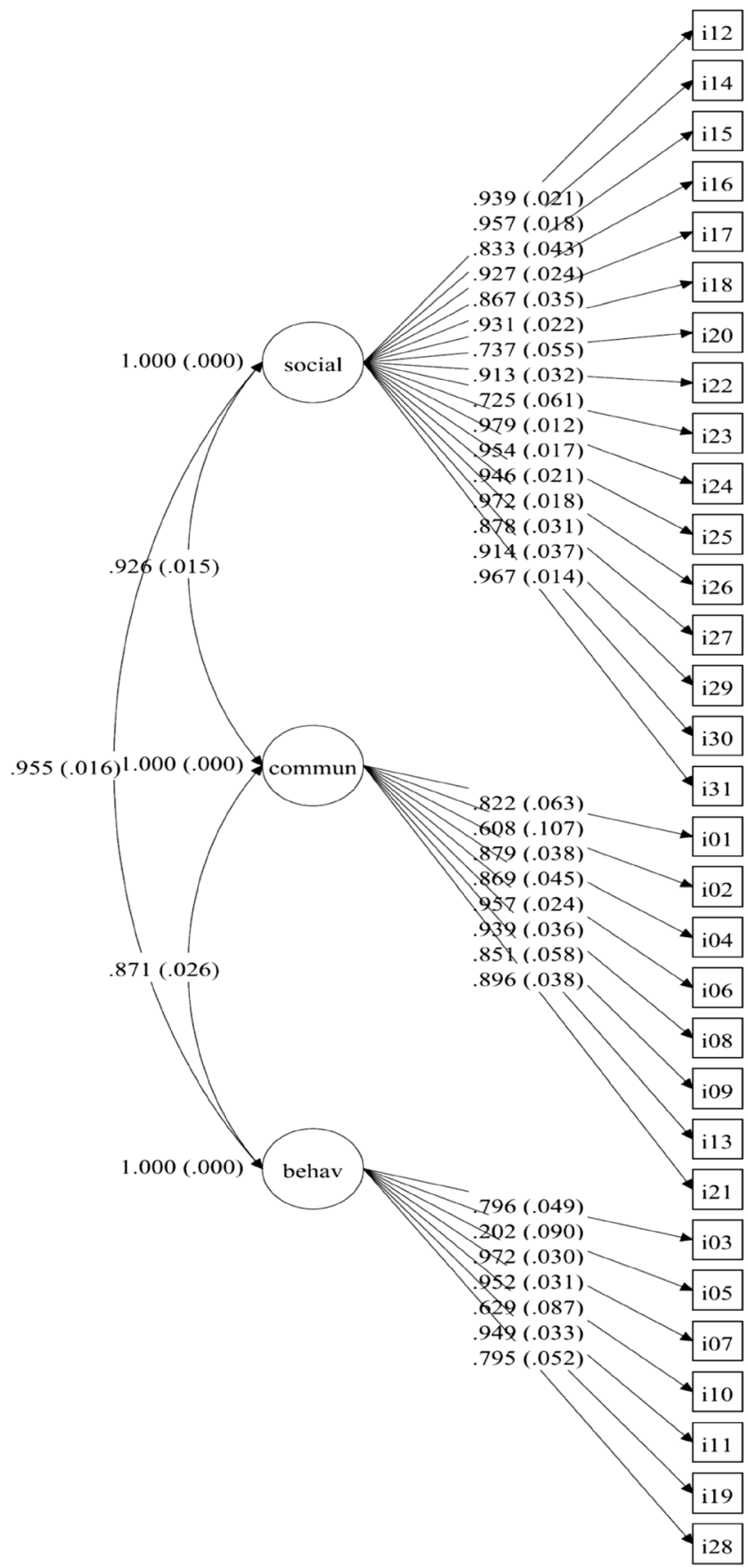

Fig. 1 Factor structure and standardized factor loadings of the ASD-DA. Notes $=$ social Scale, commun = Communication Scale, behav = Behavioral Scale. Numbers within parentheses indicate standard errors

even though the patients were divided into two groups to detect differences in the scales. It is difficult to find substantial numbers of participants with ASD and ID 
(Bishop and Norbury 2002; Garfin et al. 1988; Moore and Goodson 2003; Yirmiya et al. 1994). This study aims to contribute to the development of knowledge in the identification of ASD in adults with more severe levels of ID. It has been found that as the level of development decreases and the level of ID increases, the difficulties in obtaining an accurate diagnosis of autism increase.

Our study has several limitations. The results of this study were based on inpatients only, which may limit the generalizability of the results to people in the community

Table 3 Test-retest reliability for the ASD - DA using Cohen's kappa $(n=49)$

\begin{tabular}{lr}
\hline ASD-DA Item & Kappa \\
\hline
\end{tabular}

1. Communication skills.

2. Age appropriate self-help and adaptive skills(i.e., able to take care of self).

3. Engages in repetitive motor movements for no reason (e.g., hand waving, body rocking, head banging, hand flapping).

4. Verbal communication

5. Prefers clothing of a certain texture.

6. Ability to recognize the emotions of others.

7. Maintains eye contact.

8. Use of language to communicate.

9. Social interaction with others his/her age.

10. Response to others' social cues.

11. Reaction to normal, everyday lights (e.g., streetlights, etc.).

12. Peer relationships

13. Use of language in conversation with others.

14. Shares enjoyment, interests, achievements with others (e.g., parents, friends, caregivers).

15. Ability to make and keep friends.

16. Interest in participating in social games, sports, and activities.

17. Interest in another person's side of the conversation (e.g., talks to people with intention of hearing .783** what others have to say).

18. Use of too few or too many social gestures.

19. Likes affection (e.g., praise, hugs).

20. Awareness of the unwritten or unspoken rules of social play (e.g., turn taking, sharing).

21 . Reads nonverbal cues (body language) of other people

22. Curiosity with surroundings.

23. Responds to others' distress.

24. Socializes with other adults.

25. Use of nonverbal communication

26. Limited number of interests.

27. Imitation of an adult model (e.g., caregiver waves "bye then the individual waves "bye").

28. Abnormal, repetitive hand or arm movements.

29. Development of social relationships.

30. Isolates self (i.e., wants to be by him/herself).

31.Participation in games or other social activities.

$* p<0.01 ; * * p 0.001$; \# Insufficient variance to compute kappa 


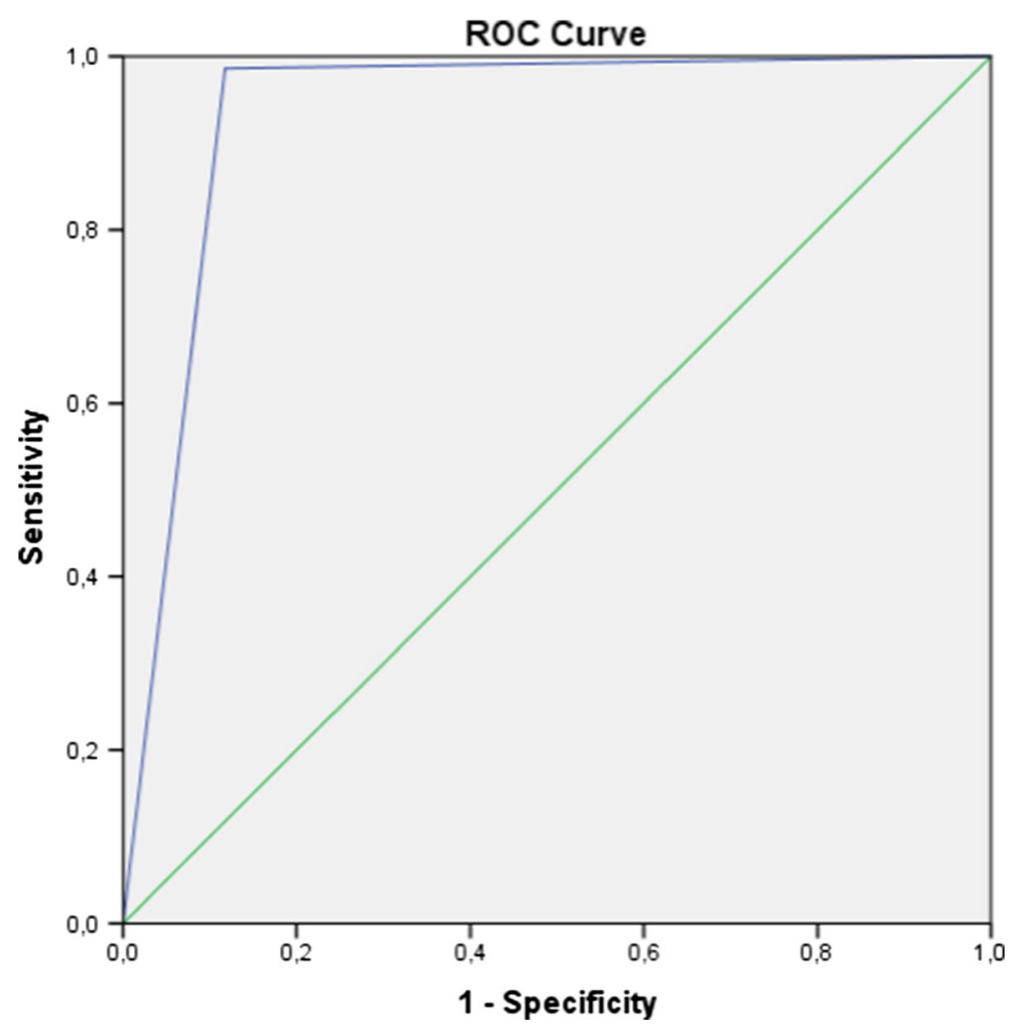

Fig. 2 ROC graph of ASD-DA score and DSM-IV-TR criteria

with less severe symptomatology. Another limitation of our study is that the inter-rater reliability of the ASD-DA was not obtained. Our sample did not include subjects at all levels of ID. The diagnostic process should include multiple informants and persons from different professions (Ozonoff et al. 2005). In the field of ASD, it has been demonstrated that the combined use of existing measures can strengthen the screening process in a population that is also at risk of having ASD (Kim and Lord 2012; Mutsaerts et al. 2016; Risi et al. 2006).

Table 4 Sensitivity, specificity, area under the curve (AUC) for ROC analysis for target cut-off scores

\begin{tabular}{llllll}
\hline Score & Sensitivity & Specificity & $\begin{array}{l}\text { Total correct } \\
\text { classification }(\%)\end{array}$ & AUC & S.E. \\
\hline 17 & 1.00 & .81 & 89.7 & .939 & .023 \\
18 & .98 & .83 & 90.4 & .939 & .023 \\
19 & .98 & .88 & 92.9 & .934 & .022 \\
20 & .97 & .91 & 94.2 & .939 & .023 \\
21 & .97 & .92 & 94.9 & .939 & .023 \\
22 & .93 & .94 & 93.6 & .939 & .023 \\
23 & .90 & .95 & 92.9 & .939 & .023 \\
24 & .90 & .97 & 94.2 & .939 & .023 \\
28 & .33 & 1.0 & 69.9 & .939 & .023 \\
\hline
\end{tabular}


In conclusion, the internal consistency and test-retest reliability of the ASD-DA scale were good, and the scale discriminated patients with severe / profound ID and ASD from those who did not have ASD. When translated and adapted to Spanish, the factorial structure of the ASD-DA scale was stable. Thus, the results of the validation of the ASD-DA scale demonstrate that the instrument can be used reliably in Spanish samples. To the best of our knowledge, no other adaptations of the ASD-DA scale have been made in other countries to date; therefore, the results of the Spanish version cannot be compared with those obtained for other versions.

\section{Compliance with Ethical Standards}

Role of the Funding Source This study received no funding source.

Ethical Approval All procedures performed in studies involving human participants were in accordance with the ethical standards of the institutional and/or national research committee and with the 1964 Helsinki declaration and its later amendments or comparable ethical standards.

Conflict of Interest I Planelles-Fernández, D Gallardo-Pujol, A Labad, D Godall, N Cristia and JA Gutiérrez-Zotes declare that they have no conflicts of interest concerning this article. Deann Matson, Dr. Johnny L. Matson's wife, is the sole owner of the Autism Spectrum Disorders- Diagnosis for Adults (ASD-DA) and sells the scale.

\section{Appendix 1}

\section{Spanish version of ASD-DA scale}

(Escala de Diagnóstico de Trastornos del Espectro Autista para Adultos con Discapacidad Intelectual).

\footnotetext{
Puntúe cada ítem en la medida en que sea o haya sido un problema alguna vez. Compare a la persona con otras de su edad (que vivan en la comunidad) basándose en lo siguiente:

$0=$ No es diferente. No tiene discapacidad. 1 = Diferente. Alguna discapacidad.

1. Habilidades de comunicación.

2. Habilidades de autoayuda y adaptativas adecuadas a su edad (por ejemplo: ser capaz de cuidar de sí mismo).

3. Incurre en movimientos motores repetitivos sin ninguna razón (por ejemplo: agita la mano, balancea el cuerpo, se golpea la cabeza, hace aleteos con las manos).

4. Comunicación verbal.

5. Prefiere la ropa de una determinada textura.

6. Capacidad para reconocer las emociones de los demás.

7. Mantiene contacto ocular.

8. Uso del lenguaje para comunicarse.

9. Interacciones sociales con otros de su edad.

10. Responde a las señales sociales de los demás.

11. Reacción a las luces normales diarias (por ejemplo: semáforos, etc)

12. Relaciones con compañeros.
} 
13. Uso del lenguaje en conversaciones con los demás.

14. Comparte el disfrute, intereses o logros con los demás (por ejemplo: padres, amigos, cuidadores)

15. Capacidad para hacer y mantener amigos

16. Interés en participar en juegos, deportes y actividades sociales

17. Interés en la opinión expresada por otra persona en una conversación (por ejemplo: habla con las personas con la intención de escuchar lo que tienen que decir)

18. Uso de muy pocos o demasiados gestos sociales

19. Le gustan las muestras de afecto (por ejemplo: halagos, abrazos)

20. Conciencia de las normas no escritas o no habladas del juego social (por ejemplo: esperar el turno, compartir)

21. Lee la comunicación no verbal (lenguaje corporal) de otras personas (si está ciego, puntuar "0").

22. Curiosidad por lo que le rodea.

23. Responde ante el estrés de los demás.

24. Se socializa con otros adultos.

25. Uso de la comunicación no verbal.

26. Limitado número de intereses.

27. Imitación de un modelo adulto o infantil (ejemplo: el cuidador dice adiós con la mano entonces el niño dice adiós con la mano).

28. Movimientos de manos o brazos anormales o repetitivos.

29. Desarrollo de relaciones sociales.

30. Se aísla (ejemplo: quiere estar solo/sola).

31. Participación en juegos u otras actividades sociales.

\section{References}

Allen, C. W., Silove, N., Williams, K., \& Hutchins, P. (2007). Validity of the social communication questionnaire in assessing risk of autism in preschool children with developmental problems. Journal of Autism and Developmental Disorders, 37(7), 1272-1278. doi:10.1007/s10803-006-0279-7.

Aman, M. G., Singh, N. N., Stewart, A. W., \& Field, C. J. (1985). The aberrant behavior checklist: A behavior rating scale for the assessment of treatment effects. American Journal of Mental Deficiency, 89(5), 485$491 \mathrm{http}: / /$ www.ncbi.nlm.nih.gov/pubmed/3993694.

American Psychiatric Association. (2000). Diagnostic and statistical of mental disorders. (American Psychiatric Association, Ed.) (4th eds, t.). Washington, DC.

American Psychiatric Association. (2013). Diagnostic and statistical manual of mental disorders. Arlington. doi:10.1176/appi.books.9780890425596.744053.

Arvio, M., \& Sillanpää, M. (2003). Prevalence, aetiology and comorbidity of severe and profound intellectual disability in Finland. Journal of Intellectual Disability Research, 47(2), 108-112. doi:10.1046/j.13652788.2003.00447.x.

Bergmann, T., Sappok, T., Diefenbacher, A., Dames, S., Heinrich, M., Ziegler, M., \& Dziobek, I. (2015). Music-based autism diagnostics (MUSAD) - a newly developed diagnostic measure for adults with intellectual developmental disabilities suspected of autism. Research in Developmental Disabilities, 4344, 123-135. doi:10.1016/j.ridd.2015.05.011.

Bergmann, T., Heinrich, M., Ziegler, M., Dziobek, I., Diefenbacher, A., \& Sappok, T. (2016). MUSAD: validation of the music-based scale for autism diagnosis in adults with intellectual disability. Nordic Journal of Music Therapy, 25(sup1), 11-11. doi:10.1080/08098131.2016.1179883.

Bishop, D. V. M., \& Norbury, C. F. (2002). Exploring the borderlands of autistic disorder and specific language impairment: A study using standardised diagnostic instruments. Journal of Child Psychology and Psychiatry, and Allied Disciplines, 43(7), 917-929 http://www.ncbi.nlm.nih.gov/pubmed/12405479.

Bruininks, R., Hill, B., Weatherman, R., \& Woodcock, R. (1986). Examiner's manual. ICAP: Inventory for client and agency planning. Allen: DLM Teaching Resources. 
Bryson, S. E., Bradley, E. A., Thompson, A., \& Wainwright, A. (2008). Prevalence of autism among Adoledcents with intellectual disabilities. The Canadian Journal of Psychiatry, 53(3), 449-460.

Cervantes, P. E., \& Matson, J. L. (2015). Comorbid symptomology in adults with autism Spectrum disorder and intellectual disability. Journal of Autism and Developmental Disorders, 45(12), 3961-3970. doi:10.1007/s10803-015-2553-z.

Charman, T., Taylor, E., Drew, A., Cockerill, H., Brown, J.-A., \& Baird, G. (2005). Outcome at 7 years of children diagnosed with autism at age 2: Predictive validity of assessments conducted at 2 and 3 years of age and pattern of symptom change over time. Journal of Child Psychology and Psychiatry, and Allied Disciplines, 46(5), 500-513. doi:10.1111/j.1469-7610.2004.00377.x.

de Bildt, A., Sytema, S., Ketelaars, C., Kraijer, D., Volkmar, F., \& Minderaa, R. (2003). Measuring pervasive developmental disorders in children and adolescents with mental retardation: A comparison of two screening instruments used in a study of the total mentally retarded population from a designated area. Journal of Autism and Developmental Disorders, 33(6), 595-605 http://www.ncbi.nlm.nih.gov/pubmed/14714929. Accessed 30 June 2015.

DiLavore, P. C., Lord, C., \& Rutter, M. (1995). The pre-linguistic autism diagnostic observation schedule. Journal of Autism and Developmental Disorders, 25(4), 355-379. http:/www.ncbi.nlm.nih. gov/pubmed/7592249. Accessed 30 June 2015

Fletcher, R., Loschen, E., Stavrakaki, C., \& First, M. (Eds.). (2007). Diagnostic manual - intellectual disability (DM-ID): A textbook of diagnosis of mental disorders in persons with intellectual disability. Kingston: NADD Press http://www.dmid.org/text-intro.htm. Accessed 25 August 2015.

Fombonne, E. (2011). Epidemiology of pervasive developmental disorders. Autism spectrum disorders, 65(September), 90-111. doi:10.1093/med/9780195371826.003.0007.

Garfin, D. G., McCallon, D., \& Cox, R. (1988). Validity and reliability of the childhood autism rating scale with autistic adolescents. Journal of Autism and Developmental Disorders, 18(3), 367-378 http://www. ncbi.nlm.nih.gov/pubmed/3170455.

Jackson, D. L., Gillaspy, J. A., \& Purc-Stephenson, R. (2009). Reporting practices in confirmatory factor analysis: An overview and some recommendations. Psychological Methods, 14(1), 6-23. doi:10.1037/a0014694.

Kim, S. H., \& Lord, C. (2012). Combining information from multiple sources for the diagnosis of autism spectrum disorders for toddlers and young preschoolers from 12 to 47 months of age. Journal of Child Psychology and Psychiatry, and Allied Disciplines, 53(2), 143-151. doi:10.1111/j.1469-7610.2011.02458.x.

Kim, Y. S., Leventhal, B. L., Koh, Y.-J., Fombonne, E., Laska, E., Lim, E.-C., et al. (2011). Prevalence of autism spectrum disorders in a total population sample. The American Journal of Psychiatry, 168(9), 904 912. doi:10.1176/appi.ajp.2011.10101532.

Kraijer, D., \& de Bildt, A. (2005). The PDD-MRS: An instrument for identification of autism spectrum disorders in persons with mental retardation. Journal of Autism and Developmental Disorders, 35(4), 499-513. doi:10.1007/s10803-005-5040-0.

La Malfa, G., Lassi, S., Bertelli, M., Salvini, R., \& Placidi, G. F. (2004). Autism and intellectual disability: A study of prevalence on a sample of the Italian population. Journal of Intellectual Disability Research, 48(3), 262-267. doi:10.1111/j.1365-2788.2003.00567.x.

La Malfa, G., Lassi, S., Salvini, R., Giganti, C., Bertelli, M., \& Albertini, G. (2007). The relationship between autism and psychiatric disorders in intellectually disabled adults. Research in Autism Spectrum Disorders, 1(3), 218-228. doi:10.1016/j.rasd.2006.10.004.

Lord, C., \& Bailey, A. (2002). Autism spectrum disorders. In E. T. M. Rutter (Ed.), Child and adolescent psychiatry (pp. 664-681). Oxford: Blackwell Scientific.

Lord, C., Rutter, M., Goode, S., Heemsbergen, J., Jordan, H., Mawhood, L., \& Schopler, E. (1989). Autism diagnostic observation schedule: A standardized observation of communicative and social behavior. Journal of Autism and Developmental Disorders, 19(2), 185-212 http://www.ncbi.nlm.nih.gov/pubmed/2745388.

Lord, C., Rutter, M., \& Le Couteur, A. (1994). Autism diagnostic interview-revised: A revised version of a diagnostic interview for caregivers of individuals with possible pervasive developmental disorders. Journal of Autism and Developmental Disorders, 24(5), 659-685 http://www.ncbi.nlm.nih. gov/pubmed/7814313.

Magnússon, P., \& Sæmundsen, E. (2001). Prevalence of autism in Iceland. Journal of Autism and Developmental Disorders, 31(2), 153-163. doi:10.1023/A:1010795014548.

Marsh, H. W., Wen, Z., \& Hau, K.-T. (2004). Structural equation models of latent interactions: Evaluation of alternative estimation strategies and indicator construction. Psychological Methods, 9(3), 275-300. doi:10.1037/1082-989X.9.3.275.

Matson, J. L., \& Boisjoli, J. A. (2008). Autism spectrum disorders in adults with intellectual disability and comorbid psychopathology: Scale development and reliability of the ASD-CA. Research in Autism Spectrum Disorders, 2(2), 276-287. doi:10.1016/j.rasd.2007.07.002. 
Matson, J. L., \& Rivet, T. T. (2007). A validity study of the autism Spectrum Sisorders-behavior problems for adults (ASD-BPA) scale. Journal of Developmental and Physical Disabilities, 19(6), 557-564. doi:10.1007/s10882-007-9069-1.

Matson, J. L., \& Shoemaker, M. (2009). Intellectual disability and its relationship to autism spectrum disorders. Research in Developmental Disabilities, 30(6), 1107-1114. doi:10.1016/j.ridd.2009.06.003.

Matson, J. L., Gardner, W. I., Coe, D. A., \& Sovner, R. (1991). A scale for evaluating emotional disorders in severely and profoundly mentally retarded persons. Development of the diagnostic assessment for the severely handicapped (DASH) scale. The British Journal of Psychiatry : the Journal of Mental Science, 159, 404-409 http://www.ncbi.nlm.nih.gov/pubmed/1958951. Accessed 9 June 2016.

Matson, J. L., Leblanc, L. A., \& Weinheimer, B. (1999). Reliability of the Matson evaluation of social skills in individuals with severe retardation (MESSIER). Behavior Modification, 23(4), 647-661 http://www.ncbi. nlm.nih.gov/pubmed/10533445.

Matson, J. L., Wilkins, J., \& González, M. (2007a). Reliability and factor structure of the autism spectrum disorders-diagnosis scale for intellectually disabled adults (ASD-DA). Journal of Developmental and Physical Disabilities, 19(6), 565-577. doi:10.1007/s10882-007-9070-8.

Matson, J. L., Boisjoli, J. A., González, M. L., Smith, K. R., \& Wilkins, J. (2007b). Norms and cut off scores for the autism spectrum disorders diagnosis for adults (ASD-DA) with intellectual disability. Research in Autism Spectrum Disorders, 1(4), 330-338. doi:10.1016/j.rasd.2007.01.001.

Matson, J. L., Wilkins, J., Boisjoli, J. A., \& Smith, K. R. (2008). The validity of the autism spectrum disordersdiagnosis for intellectually disabled adults (ASD-DA). Research in Developmental Disabilities, 29(69), 537-546. doi:10.1016/j.ridd.2007.09.006.

McCarthy, J., Hemmings, C., Kravariti, E., Dworzynski, K., Holt, G., Bouras, N., \& Tsakanikos, E. (2010). Challenging behavior and co-morbid psychopathology in adults with intellectual disability and autism spectrum disorders. Research in Developmental Disabilities, 31(2), 362-366. doi:10.1016/j.ridd.2009.10.009.

McGovern, C. W., \& Sigman, M. (2005). Continuity and change from early childhood to adolescence in autism. Journal of Child Psychology and Psychiatry, and Allied Disciplines, 46(4), 401-408. doi:10.1111 j.1469-7610.2004.00361.x.

Moore, V., \& Goodson, S. (2003). How well does early diagnosis of autism stand the test of time? Follow-up study of children assessed for autism at age 2 and development of an early diagnostic service. Autism : the International jouRnal of Research and Practice, 7(1), 47-63 http://www.ncbi.nlm.nih.gov/pubmed/12638764.

Mutsaerts, C. G., Heinrich, M., Sterkenburg, P. S., \& Sappok, T. (2016). Screening for ASD in adults with IDmoving toward a standard using the DiBAS-R and the ACL. Journal of Intellectual Disability Research, 60(5), 512-522. doi:10.1111/jir.12290.

Nordin, V., \& Gillberg, C. (1998). The long-term course of autistic disorders: Update on follow-up studies. Acta Psychiatrica Scandinavica, 97(2), 99-108. doi:10.1111/j.1600-0447.1998.tb09970.x.

Ozonoff, S., Goodlin-Jones, B. L., \& Solomon, M. (2005). Evidence-based assessment of autism Spectrum disorders in children and adolescents. Journal of Clinical Child \& Adolescent Psychology, 34(3), 523540. doi:10.1207/s15374424jccp3403_8.

Reiss, S., Levitan, G. W., \& Szyszko, J. (1982). Emotional disturbance and mental retardation: Diagnostic overshadowing. American Journal of Mental Deficiency, 86(6), 567-574 http://www.ncbi.nlm.nih. gov/pubmed/7102729.

Risi, S., Lord, C., Gotham, K., Corsello, C., Chrysler, C., Szatmari, P., et al. (2006). Combining information from multiple sources in the diagnosis of autism spectrum disorders. Journal of the American Academy of Child and Adolescent Psychiatry, 45(9), 1094-1103. doi:10.1097/01.chi.0000227880.42780.0e.

Rutter, M., Bailey, A., \& Lord, C. (2003). Social Communication Questionnaire (SCQ). Los Angeles: Western Psychological Services.

Sappok, T., Bergmann, T., Kaiser, H., \& Diefenbacher, A. (2010). Autismus bei erwachsenen Menschen mit geistiger Behinderung. Nervenarzt, 81(11), 1333-1345. doi:10.1007/s00115-010-3098-1.

Sappok, T., Diefenbacher, A., Budczies, J., Schade, C., Grubich, C., Bergmann, T., et al. (2013). Diagnosing autism in a clinical sample of adults with intellectual disabilities: How useful are the ADOS and the ADIR? Research in Developmental Disabilities, 34(5), 1642-1655. doi:10.1016/j.ridd.2013.01.028.

Sappok, T., Budczies, J., Dziobek, I., Bölte, S., Dosen, A., \& Diefenbacher, A. (2014a). The missing link: Delayed emotional development predicts challenging behavior in adults with intellectual disability. Journal of Autism and Developmental Disorders, 44(4), 786-800. doi:10.1007/s10803-013-1933-5.

Sappok, T., Gaul, I., Bergmann, T., Dziobek, I., Bölte, S., Diefenbacher, A., \& Heinrich, M. (2014b). The diagnostic behavioral assessment for autism spectrum disorder-Revised: A screening instrument for adults with intellectual disability suspected of autism spectrum disorders. Research in Autism Spectrum Disorders, 8(4), 362-375. 
Sappok, T., Heinrich, M., \& Diefenbacher, A. (2014c). Psychometric properties of the autism-checklist (ACL) in adults with intellectual disability. Psychiatrische Praxis, 41(1), 37-44. doi:10.1055/s-0033-1343193.

Sappok, T., Diefenbacher, A., Gaul, I., \& Bölte, S. (2015). Validity of the social communication questionnaire in adults with intellectual disabilities and suspected autism spectrum disorder. American Journal on Intellectual and Developmental Disabilities, 120(3), 203-214. doi:10.1352/1944-7558-120.3.203.

Schopler, E., Reichler, R. J., DeVellis, R. F., \& Daly, K. (1980). Toward objective classification of childhood autism: Childhood autism rating scale (CARS). Journal of Autism and Developmental Disorders, 10(1), 91-103 http://www.ncbi.nlm.nih.gov/pubmed/6927682.

Seltzer, M. M., Shattuck, P., Abbeduto, L., \& Greenberg, J. S. (2004). Trajectory of development in adolescents and adults with autism. Mental Retardation and Developmental Disabilities Research Reviews, 10(4), 234-247. doi:10.1002/mrdd.20038.

Shattuck, P. T., Seltzer, M. M., Greenberg, J. S., Orsmond, G. I., Bolt, D., Kring, S., et al. (2007). Change in autism symptoms and maladaptive behaviors in adolescents and adults with an autism spectrum disorder. Journal of Autism and Developmental Disorders, 37(9), 1735-1747. doi:10.1007/s10803-006-0307-7.

Shea, V., \& Mesibov, G. (2005). Adolescents and Adults with Autism. In Volkmar, R. Paul, A. Klin (Ed.), Handbook of Autism and Pervasive Developmental Disorders. Hoboken: John Wiley and Sons.

Spencer, D., Marshall, J., Post, B., Kulakodlu, M., Newschaffer, C., Dennen, T., et al. (2013). Psychotropic medication use and polypharmacy in children with autism spectrum disorders. Pediatrics, 132(5), 833840. doi:10.1542/peds.2012-3774.

Wilkins, J., \& Matson, J. L. (2009). A comparison of social skills profiles in intellectually disabled adults with and without ASD. Behavior Modification, 33(2), 143-155. doi:10.1177/0145445508321880.

Wolf, E. J., Harrington, K. M., Clark, S. L., \& Miller, M. W. (2013). Sample size requirements for structural equation models: An evaluation of power, bias, and solution propriety. Educational and Psychological Measurement, 76(6), 913-934. doi:10.1177/0013164413495237.

World Health Organization. (1992). The ICD-10 classification of mental and Behavioural disorders. International Classification, 10, 1-267. doi:10.1002/1520-6505(2000)9:5<201.

Yirmiya, N., Sigman, M., \& Freeman, B. J. (1994). Comparison between diagnostic instruments for identifying high-functioning children with autism. Journal of Autism and Developmental Disorders, 24(3), 281-291 http://www.ncbi.nlm.nih.gov/pubmed/8050982. 